\title{
ПРОБЛЕМА ЛОГИКИ, УМА И МЫШЛЕНИЯ В ТРУДАХ АРТУРА ШОПЕНГАУЭРА
}

\author{
Петросян Гор Гургенович \\ сотрудник \\ Научный руководитель: Смирнова Наталья Юрьевна \\ сотрудник \\ Академия Федеральной службы охраны России, г. Орёл
}

Аннотация: Целью работы является рациональное исследование достаточно весомой темы, связанной с такими понятиями как значимость логики, редкость ума и способность самостоятельного мышления. В ходе написания данной работы были применены такие методы, как анализ, синтез, сравнительный и исторический анализы.

В данной статье, автор раскрывает проблемы, описанные в трудах знаменитого философа XIX столетия Артура Шопенгауэра. Логические рассуждения, анализ и обобщение с последующим выводом основываются именно на этих трудах. Дается комментарий и оценка рассуждений А. Шопенгауэра автором статьи.

Ключевые слова: Артур Шопенгауэр, проблема логики, ума и мышления, диалектика, самомышление, мыслитель, ученый, мысли собственные и чужие.

\section{THE PROBLEM OF LOGIC, MIND AND THINKING IN THE WORKS OF ARTHUR SCHOPENHAUER}

\section{Petrosyan Gor Gurgenovich Scientific adviser: Smirnova Natalia Jurevna}

\begin{abstract}
The aim of the work is a rational study of a rather weighty topic-a problem related to such things as the importance of logic, the rarity of the mind and the ability to think independently. In the course of writing this work, such methods as analysis, synthesis, comparative and at the same time historical analysis were used.

In this article, the author reveals the problems and the essence described in the works of the famous philosopher of the XIX century Arthur Schopenhauer. Actually, logical reasoning, analysis and generalization with subsequent conclusion are based


on these works. The author comments on and evaluates A. Schopenhauer's reasoning and the author's reasoning.

Key words: Arthur Schopenhauer, the problem of logic, mind and thinking, dialectics, thinking itself, thinker, scientist, thoughts of one's own and others.

\section{ПРОБЛЕМЫ ЗНАЧЕНИЯ ЛОГИКИ И РЕДКОСТИ УМА}

Как известно, такая философская дисциплина, как «Логика» существует и имеет стабильную тенденцию развития с давних пор, еще со времен Древней Греции. Само по себе - это учение о законах и формах правильного человеческого мышления.

Артур Шопенгауэр понимает логику как явление исключительно теоретическое: «Выводить мнения из мнений - вот все, чему поучает логика...» [3, с. 51]. Логика, как считает мыслитель должна и может привести только к формальной истине, но никак не к материальной, кроме того, он считает безосновательной мысль, где идет речь о получении практической выгоды, отдавая приоритет своей диалектике (как искусству беседы, в процессе которой сообщаются факты, высказываются мнения, или же как спору, в ходе которого происходит процесс развития-изменения чего-либо).

Необходимо вспомнить и основателя логики - Аристотеля. Логика Аристотеля - это «мышление о мышлении» (что-то схожее с А. Шопенгауэром есть, но не всё), в которой имеют место быть рассуждения про основные виды бытия, подпадающие под отдельные понятия и определения, а также соединения и разделения этих видов бытия, которые выражаются в суждении $[1$, c. 25]. Но не в том суть, чтобы раскрыть весь труд великого ученого, а в том, чтобы показать, что понятие и существование «бытия» в логике имеет место быть. Отчасти оно даже полезное, что дает нам возможность говорить о материальной, практической составляющей, думая и говоря, как о истине, так и о выгоде не только в теории, но и на практике.

Не будет неправильным суждение о том, что, если наука не имеет практического значения - значит это не наука, а просто-напросто «обыденное сознание» [2, с. 52], существующее по каким-либо причинам, например, локальной актуальности. Кроме того, благодаря философии, а в большей степени одного из ее разделов - логики Аристотеля - многие науки получили свое логическое переосмысление. Таким образом, мы имеем полное право считать, что все-таки практика имеет важное место в составе логики наравне с теорией. Ведь, те же самолеты и космические ракеты стали летать не из-за того, 
что про них спорили или просто обсуждали, а потому что их разрабатывали (в теории), сооружали, после чего проводили испытания (практическая полезность), что давало возможность постоянно прогрессировать в этих областях. То же самое можно сказать и про фармацевтику: пока ученые не испытают какой-нибудь препарат на опытах и будут гадать насчет его полезности и безопасности в теории - они не узнают точно, к каким последствиям он может привести.

Если говорить про редкость ума, то у А. Шопенгауэра имеется на этот счет особое мнение: правильность суждений логика предоставляет рассудку, который и характеризует, якобы, ум человека. Философ выделяет рассудок трех видов:

- «рефлективный», определяющий основной посыл суждений и заключений;

- рассудок, располагающий правилами, понятиями, абстракциями и массой отдельных примеров, данных ему наблюдением;

- «субсуммирующий», как называет его мыслитель, то есть рассудок, основывающийся на независимом мнении.

Не только рефлективный, но и остальные два вида рассудка оказываются заключенными лишь в единичных личностях и нехарактерными для всех людей; даже субсуммирующий рассудок не совсем можно приписать обыкновенному человеку, так как у большинства людей он, обычно, сильно слаб, считает А. Шопенгауэр. В добавок к этому факту можно отметить и то, что даже там, где суждение людей не совсем подкуплено личными выводами и интересами (как это часто и бывает), главным основанием они считают авторитет: идут только по чужим следам, повторяют только то, что слышали от других, и хвалят, и ругают все единственно по примеру других: «Раздались аплодисменты - они начинают аплодировать, раздается свист - и они начинают свистеть... В жизни большинства людей, наверное, нет ни одного такого случая, о котором можно было бы сказать, что они решили так поступить и поступили единственно на основании собственного рассудка. Они похожи в этом случае на овец, идущих за бараном...» [3, с. 53]. Вот к чему клонит нас автор касательно ума: не все люди способны рассуждать, мыслить и делать из этого выводы самостоятельно и независимо. На основании всего этого, А. Шопенгауэр приходит к заключению, что одним из существенных препятствий для преуспевания человеческого рода следует считать то, что люди слушают не того, кто говорит умнее всех, а того, кто говорит громче всех. 
Насчет всего этого сложно не согласиться с великим философом, но, всетаки, есть одно «но», которое сильно обращает на себя наше внимание - фраза «правильность суждений логика предоставляет рассудку» [3, с. 52]. Если рассуждать так: рассудок входит в область логики как структурный элемент, то с последующими суждениями и заключением великого философа согласиться можно. Но, если считать, что в оценке правильности суждений логика никакой роли не играет и предоставление ею права рассудку дает основание подумать, что понятие «логика» здесь не уместно, то с последующими суждениями и заключением великого философа согласиться нельзя, потому что возникает вопрос: а что такое «рассудок», раз ему выделяют такое особое внимание? Ведь, по сути, рассудок - часть мыслящего сознания, способного логически осмыслять действительность [4, с. 1265]. Таким образом, можно сделать вывод, что логика и рассудок - это близкие по отношению друг к другу понятия, а значит в какой-то степени мы можем поддержать Артура Шопенгауэра, а в какой-то и нет.

\section{ПРОБЛЕМА САМОСТОЯТЕЛЬНОГО МЫШЛЕНИЯ}

Проблема самостоятельного мышления занимает особое место в трудах А. Шопенгауэра. На наш взгляд, данная проблема является одной из тех немногих, которая сохраняет свою актуальность в наши дни. Она должна иметь и имеет тенденцию дальнейшего изучения и пропаганды, распространения, дабы максимально иметь здравомыслящее общество, следовательно, и высокоразвитое государство.

Философ считает, что если к чтению и учению еще можно себя добровольно заставить, то к мышлению этот метод применить не получится. Для мышления должен присутствовать интерес к какому-нибудь избранному предмету или области изучения. Интерес бывает объективный, свойственный для «мыслящих от природы голов», для которых мышление стоит наравне с «дыханием», и интерес бывает субъективный, существующий в обыденном для многих людей виде.

А. Шопенгауэр сравнивает между собой такие вещи, как самостоятельное мышление и чтение. В первую очередь, различие между ними сильно сказывается воздействием на ум, при этом различие огромно. Если при чтении ум испытывает полное принуждение думать о чем-то, к чему он не имеет никакой склонности, интереса, то при самостоятельном мышлении ум действует по своей воле, собственному побуждению, которое определяется внешней обстановкой или воспоминанием, касательно чего-то. Чтение может 


\section{РАЗВИТИЕ СОВРЕМЕННОЙ МОЛОДЕЖНОЙ НАУКИ: ОПЫТ ТЕОРЕТИЧЕСКОГО И ЭМПИРИЧЕСКОГО АНАЛИЗА}

лишь дать «материал» и повод для мышления, но никак не мысль, причем ясно выработанную. Здесь можно сравнить такие стороны, как сторона ученых, сторона мыслителей (в том числе самобытных) и гениев и сторона книжных философов-мыслителей. Если первые являются просто начитанными людьми, которые и делали только то, что постоянно читали, то вторые - это «двигатели человечества», которые читали непосредственно в книге вселенной; третьи же, по сути говоря, не желая никого обидеть - являются просто - напросто «недоделанными вторыми». Если с первыми все понятно, то со вторыми и третьими - не совсем. Дело в том, что самобытный мыслитель находится в таком же отношении к обыкновенному книжному философу, как очевидец к историческому исследователю. Первый говорит на основании своего собственного непосредственного знакомства с делом, картина которого ясно и понятно изображается в его сознании, второй же, затронув ту же тему, может только сказать, что говорил один, что думал другой и что полагал третий, и так далее. Сравнивая, взвешивая и критикуя это, книжный философ пытается поймать след, ведущий к истине, причем он на все сто процентов уподобляется историческому критику; картина же, всплывающая перед ним не понятна как ему самому, так и никому другому.

Артур Шопенгауэр отмечает, что самое верное средство не иметь собственных мыслей - это во всякую свободную минуту тотчас хвататься за книгу. Постоянное чтение книг просто-напросто избавляет людей от возможности самостоятельно мыслить. Как утверждает философ, чтение есть простой «суррогат» собственного мышления, то есть читая какую-нибудь литературу, человек при этом позволяет вводить в себя посторонние мысли, отодвигая в «спящий режим» производство своих собственных. Кроме того, многие книги пригодны лишь для того, чтобы продемонстрировать наличие в них ложных путей и показать плохие последствия, которые могут возникнуть в случае, если позволить им руководить собой. Способные к самомышлению, в отличие от постоянно читающих, обладают компасом, который помогает им найти истинную дорогу. Читать, по мнению великого мыслителя нужно именно тогда, когда иссякает источник собственных мыслей, что встречается довольно часто с людьми, имеющими правильное мышление и входящими в слой «умных голов».

Бывают такие случаи, когда истина достигается не сразу и при этом с большим трудом, путем собственного мышления, а бывает и так, что эту же самую истину можно спокойно найти в книге, причем не прикладывая для её 205 
поиска особых усилий. Как показывает практика, первый способ хоть и сложный, но очень результативный. «Что унаследовал от дедов ты, усвой себе, чтобы владеть наследьем», - писал Гёте [3, с. 61]. Это высказывание полностью раскрывает сущность значимости вышесказанного. При всем при этом, нужно отметить, что если книги можно брать и читать в любое время, то с самомышлением так сделать не получится: дело в том, что оно - производство собственных мыслей - происходит внезапно.

Таким образом, мы приходим к выводу, что самостоятельность мышления (самомышление) - это очень важный компонент, свойственный, в основном, не каждому. С суждениями и заключениями Артура Шопенгауэра по этому вопросу сложно не согласиться. Ценность данного явления, процесса можно заметить при его сравнении с чтением: «именно та истина ценнее, которая достигается самомышлением, так как она принимает определенный оттенок, цвет и отпечаток и крепко закрепляется на долгие времена, не исчезая в системе нашего мышления, сознания, нежели при обычном чтении» [3, с. 61]. В большинстве случаев, при разрешении каких-либо спорных вопросов, люди ссылаются на авторитеты, радуясь тому, что они, не имея и не используя собственные взгляды, рассудок - выставляют в бой чужие, пишет А. Шопенгауэр: Имя же их легион. Ибо как говорит Сенека, каждый предпочитает верить, а не рассуждать. На наш взгляд, этим людям, не стоит радоваться, а наоборот - следует сожалеть о том, что они являются «суррогатами» - носителями чужих мыслей, амбиций.

\section{Список литературы}

1. Луканин Р.К. «Органон» Аристотеля. - М. : Наука, 1984. - С. 304.

2. Лобастов Геннадий Васильевич Наука и здравый смысл: к трагикомической картине бытия и сознания // ЭСГИ. 2018. №4 (20). // URL: https://cyberleninka.ru/article/n/nauka-i-zdravyy-smysl-k-tragikomicheskoy-kartinebytiya-i-soznaniya (дата обращения: 31.03.2021).

3. Шопенгауэр А. Искусство побеждать в спорах. - М. : Эксмо, 2020. C. 128.

4. Рассудок // Толковый словарь русского языка / Под ред. Д.Н. Ушакова. - М. : Государственное издательство иностранных и национальных словарей, 1939. - Т. 3. 